\title{
The Risk Factors Associated With Early Age At First Birth Amongst Angolan Women: Evidence From The 2015-2016 Angola Demographic And Health Survey
}

\author{
T. Motsima
}

\begin{abstract}
Reducing adolescent childbearing has been a global priority since the 1994 International Conference on Population and Development. Age of a woman at first birth is significant in her life because motherhood involves a substantial commitment of time and resources, and it tends to set the stage within which other roles are assumed. There are consequences related to early age at first birth for both the mothers and the children. This paper aims to determine the factors associated with early first birth among Angolan women aged 15-49 years. Data and Methods: The data used for analysis came from the 2015-2016 MIHS of Angola which was its first DHS. The 2015-2016 Angolan MIHS collected information from 14379 women aged 15-49 years from 16109 households. Women were asked questions around ages at which they gave birth to their children. The Tarone-Ware test was used to test the equality of the survival functions. The Cox PH model was used to determine the factors that were associated with early age at first birth. Results and Conclusion: Results revealed that women who had their sexual intercourse at a young age $(\mathrm{HR}=4.66 ; \mathrm{p}<0.001)$, women who never had a termination of pregnancy $(\mathrm{HR}=1.22 ; \mathrm{p}<$ $0.001)$, women who were never married $(H R=1.19 ; p<0.001)$, women with no education $(\mathrm{HR}=3.22 ; \mathrm{p}<0.001)$, women with primary education $(\mathrm{HR}=5.08 ; \mathrm{p}<0.001)$, women with secondary education $(H R=5.06, p<0.001)$, women of Christian religion $(H R=1.10 ; p=0.035)$ and women who resided in informal houses $(\mathrm{HR}=1.30 ; \mathrm{p}<0.001)$ were significantly associated with the risk of early age at first birth.

Index Terms-Early age at first birth, early childbearing, Cox PH model, Tarone-Ware test.
\end{abstract}

\section{INTRODUCTION}

Reducing dolescent childbearing (from 10-19 years of age) has been a global priority since the 1994 International Conference on Population and Development (ICPD) [1]. According to the World Health Organization (2018) approximately 16 million girls aged 15-19 years give birth each year in developing regions [2]. Complications during pregnancy and childbirth are the leading causes of deaths for 15-19 year old girls globally [2]. Adolescent childbearing is common in sub-Saharan Africa, especially in rural areas and communities where education levels for girls and women are low [3]. Age of a woman at first birth is significant in her life because motherhood involves a substantial commitment of time and resources, and it tends to set the stage within which other roles are assumed [4]. Age at first birth is the age of the woman in years at the time the woman gave live birth to her first child [5]. Alternatively, age at first birth is the difference

Published on April 01, 2020.

T. Motsima, Tshwane University of Technology, Pretoria, South Africa.

(e-mail: Motsimat@tut.ac.za). between the mother's age and the mother's oldest child [6].

There are consequences related to early age at first birth [7] for both the mothers and the children. On one hand, the age at which a woman begins childbearing may have an effect on the woman's socio-economic status, health and population growth [7]-[8]. Early childbearing increases population growth in that women who begin childbearing at young ages are likely to have more births than equally fecund women who begin childbearing at older ages [7]. Young mothers are likely to face the risks of low educational attainment, low occupational attainment, marital instability, short birth spacing of subsequent children, birth complications, anemia, eclampsia, puerperal endometritis, pregnancy related hypertension and congenital anomalies [2], [3], [4], [6], [7], [9]. In addition to this, young mothers may suffer the greater risk of maternal mortality [7].

On the other hand, early childbearing put new-born babies at a high risk of poor health outcomes such as chronic respiratory problems, mental illnesses, cerebral palsy, low birth weight, intellectual, behavioural and academic difficulties [7], [10], [11], [12]. Children of teen mothers are less likely to complete school, have lower performance at school and are more likely to live in poverty and suffer abuse and neglect than children born to older parents [11].

Evidence indicates that early age at first birth has an effect on women during pregnancy, at childbirth and later in life [2], [3], [4], [6], [7], [9]. Mirowsky (2005) discussed the two distinct, but not exclusive views, the biodevelopment and the biosocial view [6]. According to Mirowsky (2005) the biodevelopment view suggests that the optimum age at first birth to shortly after the reproductive system is ready while the organism enjoys energy and resilience of youth [6]. Mirowsky (2005) further stated that women perform best at childbearing when they are young [6]. However, the view of Pirkle et al (2014) is different from that of Mirowsky (2005) as they stated that giving birth at a young may bring permanent physiological alterations that might increase the risk of chronic diseases and poor physical functioning in older ages [9]. The biosocial view suggests that the optimum age at first birth should be far later in adulthood, closer to the end of fecundity than to the beginning of it [6]. The biosocial view suggests that better health and survival come from delaying first birth in order to lengthen education, build wealth and to have a stable marriage [6].

Although the global adolescent birth rate declined from 65 births per 1,000 women in 1990 to 47 births per 1,000 women in 2015 and in sub-Saharan Africa it has declined from 150.2 
births per 1,000 women to 108.8 births per 1,000 women between 1960 and 2013, early age at first birth is still a global challenge as adolescent mothers still account for $11.0 \%$ of all births globally [2], [10, [13]. Women in low income countries tend to start childbearing early, have more children and face high risks during childbirth [9]. In Malawi it was found that young mothers substantially increase the risk of infant mortality [14]. In Angola it was reported that $29.0 \%$ of young women aged 15-19 years have live births and six percent $(6.0 \%)$ are pregnant for the first time [15]. Also, in Angola teenage childbearing is highest among young women with no education (58.0\%) as compared to women with secondary or higher education [15]. Although it has been reported that the adolescent birth rate of sub-Saharan Africa was as high as 108.8 births per 1,000 women in 2013 and that the percentage of early age at first birth was as high as $29.0 \%$ in Angola [15], little research has been done in sub-Saharan African countries including Angola to investigate the factors associated with early age at first birth or the consequences of having a child at a young age. Against this background, it is the aim of this paper to determine factors associated with early first birth among Angolan women aged 15-49 years. The findings of this study will provide the government of Angola and policy makers with the understanding of the consequences of early childbearing in Angola.

\section{LITERATURE REVIEW}

Age at first birth is inevitably a proxy for other factors [12]. Amongst factors reported to be associated with early age at first birth are education, economic hardship, marital instability, smoking, father's occupation, race, religion, place of residence, region, high blood pressure, diabetes and chronic disease outcomes [4], [7], [9], [16].

Rindfuss \& John (1983) examined characteristics that could affect age at first birth. The results revealed that the father's occupation, education, race, religion and place of residence had significant effects on early age at first birth [4]. Also, it was found that miscarriage or stillbirth prior to first birth had a strong delaying effect on age at first birth and smoking at a young age had a negative effect on age at first birth [4]. Morrison et al (1992) investigated the effects of being born to a young woman on child well-being by using two-stage least squares method and found that black children born to teenage mothers performed less on the Peabody Picture Vocabulary Test [12].

Khatun et al (2017) investigated the association between teenage parenthood and young adult children's Intelligence Quotient (IQ) at 21 years [10]. The Chi-square and/or Fisher's Exact tests were used for categorical data and the T-tests were used for continuous data [10]. Simple linear regressions were applied to test the trend of systematic increase or decrease of children mean IQ score over the level of parental age groups [10]. The results revealed that a greater proportion of teenage mothers did not complete high school education, had low family income, smoked cigarette, did not breastfeed for a shorter duration, had experienced depressed mood and gave birth with relatively low birth weights [10]. Children of teenage mothers had a lower IQ than children of older mothers [10].

Avogo \& Somefun (2019) used the logistic regression models to examine the relationship between individual, household and community-level characteristics on early childbearing in three sub-Saharan countries, Nigeria, Burkina Faso and Niger [16]. On community-level characteristics, the results revealed that women with medium or higher education reduced the risk of early childbearing in Nigeria [16]. On individual characteristics, the results revealed that women's education at secondary or higher level significantly reduced the risk of early childbearing in Nigeria and Burkina Faso [16]. Women of lower educational attainment, women from poorest households, women of Christian religion, women from female headed households, women who resided in the Southern region and women who resided in rural areas significantly increased the risk of early childbearing in Nigeria [16].

Mirowsky (2005) investigated the relationship of age at first birth with women's subsequent health and survival throughout adulthood and found that women's health benefits from delaying motherhood [6]. These results contradict the biodevelopment view, but are consistent with the biosocial view discussed by [6]. Pirkle et al (2014) used the logistic regression models to assess the associations between age at first birth and independent variables [9]. The results revealed significant association between age at first birth and number of chronic disease outcomes, high blood pressure, diabetes, chronic lung disease [9].

\section{DATA AND METHODS}

\section{A. Data}

The data used for analysis came from the 2015-2016 Multiple Indicator and Health Survey (MIHS) of Angola which was its first Demographic and Health Survey and its fourth Multiple Indicator Cluster Survey [17]. The 2015-2016 Angolan MIHS was a nationally representative survey that collected information from 14379 women aged 15-49 years who were from 16109 households [17]. The 2015-2016 MIHS collected information on fertility, childbirth care, child mortality, maternal mortality, knowledge and practice around contraception, knowledge and attitudes about sexually transmitted diseases, communicable diseases and HIV/AIDS, amongst others [17]. Women were asked questions around ages at which they gave birth to their children [17].

\section{B. Variables}

The dependent or outcome variable was whether the woman had her first child at age 18 years or younger or at age above 18 years. The dependent variable was coded as 1 if the woman had her first birth at age 18 years or younger, otherwise it was coded as 0 if the woman had her first birth at age over 18 years. The cut-off age of 18 years was chosen because the median age at first sex for Angolan women was reportedly 16.7 years from the 2015-2016 MIHS [15]. For a 
woman to fall pregnant she must engage into a sexual activity first hence the age beyond the median age was chosen as a cut-off point. Pirkle et al (2014) used the same cut-off point of age at first birth to examine the relationships between age at first birth and multi-parity on chronic diseases and poor physical function in older ages [9]. The independent or explanatory variables considered were age at first sexual intercourse, child mortality status, pregnancy termination (abortion), contraception, total number of children, marital status, education, religion and type of house.

\section{The Log-rank test and the Tarone-ware test}

The Mantel's generalization of the Savage test, popularly known as the log-rank test is a non-parametric statistical test that is used to test the equality of survivor functions [18]. The log-rank test can handle censored data and it does not test the equality of the survivor functions at a specific time point, but it is a global test that compares the overall survival functions [18]-[19]. The log-rank test requires that the hazard ratio of the two groups should be proportional [20]. It compares outcomes over the whole time interval, may not adequately detect important differences between groups which occur either early or late in the interval [20].

The Tarone-Ware test gives more weight to events that occur earlier when more subjects are at risk [19]-[20]. As a result it is less susceptible to problems should there exist vast differences in the censoring patterns among the groups [19]. The Tarone-Ware test uses the square root of the number of subjects at risk as weight $W\left(t_{i}\right)=\sqrt{n_{i}}$ [19]-[20]. The test can compare the equality of survival functions of more than two groups and can be used when the survival curves cross [21]- [22] and it is regarded as superior to the log-rank test [21]. Due to the advantages of the Tarone-Ware test over the log-rank test, the Tarone-Ware test was used to test the equality of the survival functions. Also, the Tarone-Ware test was chosen because some variables have more than two categories.

\section{The Cox Proportional Hazards model}

The Cox (1972) proportional hazards ( $\mathrm{PH})$ model is the semi-parametric model that is used to analyse survival data [19], [23]. The Cox PH model is semi-parametric in that it does not require any particular form of the distribution, but the model is based on the assumptions of proportional hazards [18], [23], [24], [26]. The Cox PH model states that the hazard rate for the $i$ th mother in the data is:

$$
h\left(t, \mathbf{x}_{i}\right)=h_{0}(t) \exp \left(\mathbf{x}_{i} \boldsymbol{\beta}_{x}\right)
$$

where $\mathbf{x}_{i}$ is the covariate vector and the $\boldsymbol{\beta}_{x}$ are the regression coefficients estimated from the data [19], [23], [24]. The general form of the Cox PH model gives an expression for the hazards at time $t$ for the mother with a specification of a set of explanatory variables denoted by $\mathbf{x}$ [23], [24], [25]. Comparing mother $i$ to mother $m$ the Cox $\mathrm{PH}$ model states that the ratio of their hazards at time $t$ is:

$$
\frac{h\left(t \mid \mathbf{x}_{i}\right)}{h\left(t \mid \mathbf{x}_{m}\right)}=\frac{\exp \left(\mathbf{x}_{i} \boldsymbol{\beta}_{x}\right)}{\exp \left(\mathbf{x}_{m} \boldsymbol{\beta}_{x}\right)}=\exp \left\{\boldsymbol{\beta}_{x}\left(\mathbf{x}_{i}-\mathbf{x}_{m}\right)\right\}
$$

which is constant, assuming the covariates $\mathbf{x}_{i}$ and $\mathbf{x}_{m}$ do not change over time, that is, the hazards are proportional $\left[h\left(t \mid \mathbf{x}_{i}\right) \propto h\left(t \mid \mathbf{x}_{m}\right)\right]$ to each other and are independent of time [18], [19], [23], [24], [26]. This term $\exp \left\{\boldsymbol{\beta}_{x}\left(\mathbf{x}_{i}-\mathbf{x}_{m}\right)\right\}$ is called the hazard ratio comparing $\mathbf{x}_{i}$ to $\mathbf{x}_{m}$ [23], [24], [26]. The Cox PH assumption was assessed using the observed versus predicted curves method [24]-[25]. The Cox PH model was used to determine the risk factors that were associated with early age at first birth.

\section{RESULTS}

Table 1 presents the summary statistics of the variables as well as the results of the Tarone-Ware tests. For the sake of this paper first births that occurred at age 18 years or younger are referred to as young age (or early) and first births that occurred at ages over 18 years are referred to as old age (or late). The results show that $5884(44.8 \%)$ had their first births at an old age and $7263(55.2 \%)$ had their first births at a young age. Of the 3955 women who had their first sexual intercourse at ages over 16 years $3026(76.5 \%)$ had their first births at an old age and $929(23.5 \%)$ had their first births at a young age. Of the 9192 women who had their first sexual intercourse at 16 years of age or younger $2858(31.1 \%)$ had their first births at an old age and 6334 (68.9\%) had their first births at a young age. Of the 12499 under-five years children who were alive at the time the data were collected 5638 (45.1\%) were children of mothers who had their first births at an old age and $6861(54.9 \%)$ were children of mothers who had their first births at a young age. Of the 648 under-five years children who were not alive at the time the data were collected $246(38.0 \%)$ were children of mothers who had their first births at an old age and $402(62.0 \%)$ were children of mothers who had their first births at a young age.

Of the 1300 women who had a termination of pregnancy $590(45.4 \%)$ had their first births at an old age and 710 (54.6\%) had their first births at a young age. Of the 11847 women who did not have a termination of pregnancy 5294 (44.7\%) had their first births at an old age and 6553 (55.3\%) had their first births at a young age. Of the 11948 women who do not use contraception $5312(44.5 \%)$ had their first births at an old age while $6636(55.5 \%)$ had their first births at a young age. Of the 1199 women who use contraception $572(47.7 \%)$ had their first births at an old age while 627 (52.3\%) had their first births at a young age.

Of the 4327 women who had a total of one or two children 1921 (44.4\%) had their first births at an old age while 2406 $(55.6 \%)$ had their first births at a young age. Of the 4214

TABLE I

SUMMARY STATISTICS AND THE TARONE-WARE TESTS 


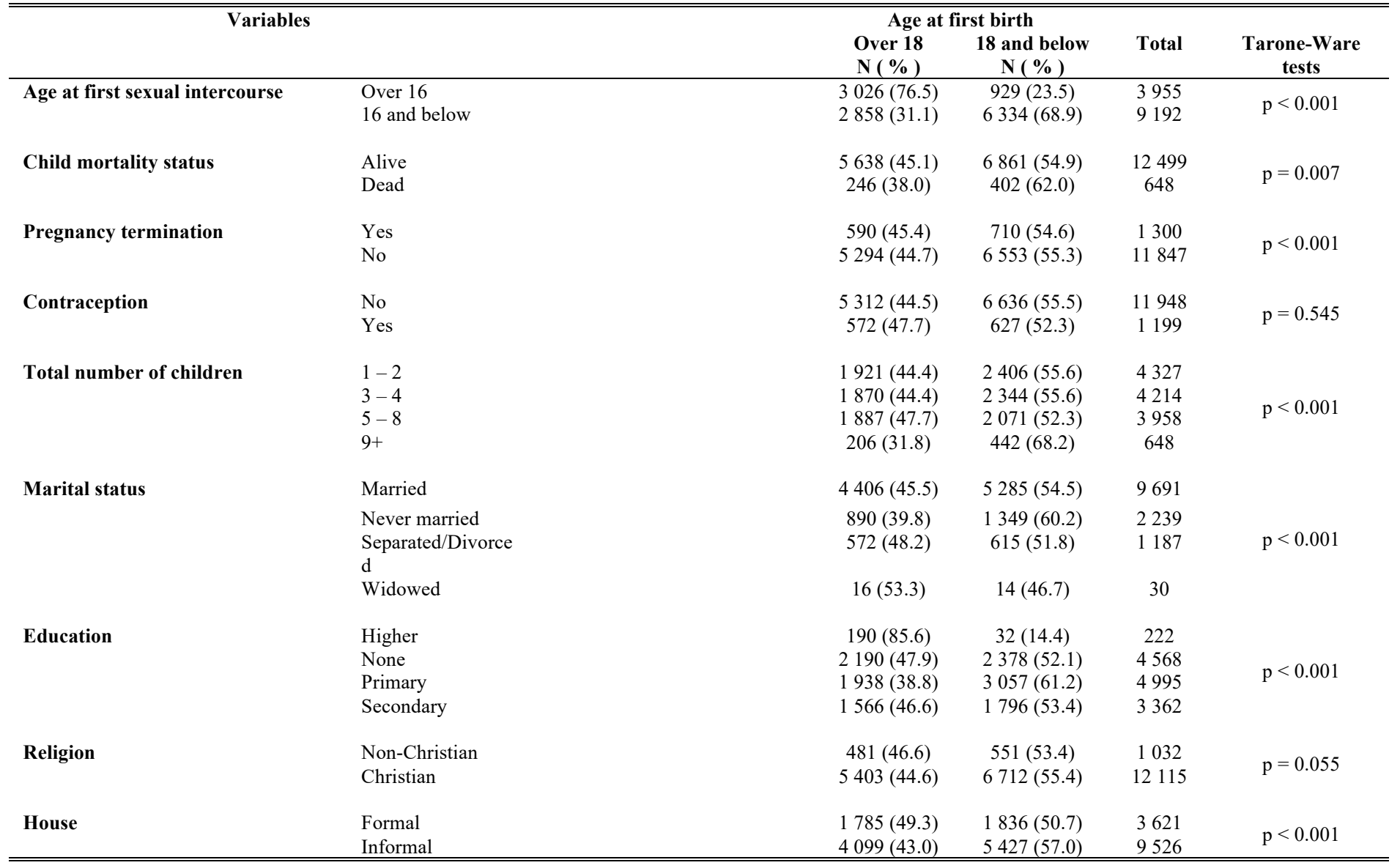

women who had a total of three or four children 1870 (44.4\%) had their first births at an old age while 2344 $(55.6 \%)$ had their first births at a young age. Of the 3958 women who had a total of five to eight children 1887 $(47.7 \%)$ had their first births at an old age while 2071 $(52.3 \%)$ had their first births at a young age. Of the 648 women who had a total of nine or more children $206(31.8 \%)$ had their first births at an old age while $442(68.2 \%)$ had their first births at a young age.

Of the 9691 women who were married 4406 (45.5\%) had their first births at an old age and 5285 (54.5\%) had their first births at a young age. Of the 2239 women who were never married $890(39.8 \%)$ had their first births at an old age and $13409(60.2 \%)$ had their first births at a young age. Of the 1187 women who were separated or divorced from their partners $572(48.2 \%)$ had their first births at an old age and $615(51.8 \%)$ had their first births at a young age. Of the 30 widowed women $16(53.3 \%)$ had their first births at an old age and $14(46.7 \%)$ had their first births at a young age.

Of the 222 women with higher education $190(85.6 \%)$ had their first births at an old age and 32 (14.4\%) had their first births at a young age. Of the 4568 women who had no education, $2190(47.9 \%)$ had their first births at an old age and $2378(52.1 \%)$ had their first births at a young age. Of the 4995 women with primary education 1938 (38.8\%) had their first births at an old age and 3057 (61.2\%) had their first births at a young age. Of the 3362 women with secondary education $1566(46.6 \%)$ had their first births at an old age and 1796 (53.4\%) had their first births at a young age.

Of the 12115 Christian women $5403(44.6 \%)$ had their first births at an old age and $6712(55.4 \%)$ had their first births at a young age while of the 1032 non-Christian women $481(46.6 \%)$ had their first births at an old age and 551 (53.4\%) had their first births at a young age. Of the 3621 women who stayed in formal houses $1785(49.3 \%)$ had their first births at an old age and $1836(50.7 \%)$ had their first births at a young age while of the 9526 women who stayed in informal houses $4099(43.0 \%)$ had their first births at an old age and 5427 (57.0\%) had their first births at a young age.

The Tarone-Ware tests results showed that there were significant differences between the survival functions of late age at first sexual intercourse and early age at first sexual intercourse $(p<0.001)$, between children who were alive up to the age of five years and those who were not alive up to the age of five years $(p=0.007)$, between women who had pregnancy termination and women who did not $(\mathrm{p}<0.001)$, between women who a total of one or two children and women who had a total of three to four children, five to eight children and more than nine children $(p<0.001)$, between women with higher education level and women with no 


\begin{tabular}{|c|c|c|c|}
\hline & $D_{1}$ & Univariate $\mathrm{C}$ & $\mathbf{P H}$ \\
\hline & raves & HR (p-value) & S.E \\
\hline Age at first & Over 16 & $(-)$ & $(-)$ \\
\hline & 16 and below & $3.72(\mathrm{p}<0.001)$ & 0.131 \\
\hline Child mortality & Alive & $(-)$ & $(-)$ \\
\hline status & Dead & $1.17(\mathrm{p}=0.002)$ & 0.060 \\
\hline Pregnancy & Yes & $(-)$ & $(-)$ \\
\hline & No & $1.34(\mathrm{p}<0.001)$ & 0.053 \\
\hline Contraception & No & $(-)$ & $(-)$ \\
\hline & Yes & $1.06(\mathrm{p}=0.155)$ & 0.044 \\
\hline Total number of & $1-2$ & $(-)$ & $(-)$ \\
\hline & $3-4$ & $0.47(\mathrm{p}<0.001)$ & 0.014 \\
\hline & $5-8$ & $0.23(\mathrm{p}<0.001)$ & 0.007 \\
\hline & $9+$ & $0.18(\mathrm{p}<0.001)$ & 0.010 \\
\hline Marital status & Married & $(-)$ & $(-)$ \\
\hline & Never married & $1.89(\mathrm{p}<0.001)$ & 0.058 \\
\hline & Separated/Divorced & $0.87(\mathrm{p}=0.001)$ & 0.037 \\
\hline & Widowed & $0.81(\mathrm{p}=0.421)$ & 0.216 \\
\hline Education & Higher & $(-)$ & $(-)$ \\
\hline & None & $3.59(\mathrm{p}<0.001)$ & 0.638 \\
\hline & Primary & $4.81(\mathrm{p}<0.001)$ & 0.854 \\
\hline & Secondary & $5.41(\mathrm{p}<0.001)$ & 0.965 \\
\hline Religion & Non-Christian & $(-)$ & $(-)$ \\
\hline & Christian & $1.08(\mathrm{p}=0.078)$ & 0.048 \\
\hline House & Formal & $(-)$ & $(-)$ \\
\hline & Informal & $1.14(\mathrm{p}<0.001)$ & 0.031 \\
\hline
\end{tabular}

TABLE III

RESULTS FROM THE MULTIVARIATE COX PH MODEL

\begin{tabular}{|c|c|c|c|}
\hline \multirow{2}{*}{\multicolumn{2}{|c|}{ Variables }} & \multicolumn{2}{|c|}{ 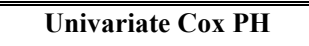 } \\
\hline & & HR (p-value) & S.E \\
\hline \multirow{2}{*}{$\begin{array}{l}\text { Age at first } \\
\text { sexual } \\
\text { intercourse }\end{array}$} & Over 16 & $(-)$ & $(-)$ \\
\hline & 16 and below & $4.66(\mathrm{p}<0.001)$ & 0.166 \\
\hline \multirow{2}{*}{$\begin{array}{l}\text { Child mortality } \\
\text { status }\end{array}$} & Alive & $(-)$ & $(-)$ \\
\hline & Dead & $1.38(\mathrm{p}<0.001)$ & 0.071 \\
\hline \multirow{2}{*}{$\begin{array}{l}\text { Pregnancy } \\
\text { termination }\end{array}$} & Yes & $(-)$ & $(-)$ \\
\hline & No & $1.22(\mathrm{p}<0.001)$ & 0.049 \\
\hline \multirow[t]{2}{*}{ Contraception } & No & $(-)$ & $(-)$ \\
\hline & Yes & $1.02(p=0.611)$ & 0.045 \\
\hline \multirow{4}{*}{$\begin{array}{l}\text { Total number of } \\
\text { children }\end{array}$} & $1-2$ & $(-)$ & $(-)$ \\
\hline & $3-4$ & $0.40(\mathrm{p}<0.001)$ & 0.012 \\
\hline & $5-8$ & $0.18(\mathrm{p}<0.001)$ & 0.006 \\
\hline & $9+$ & $0.12(\mathrm{p}<0.001)$ & 0.007 \\
\hline \multirow[t]{4}{*}{ Marital status } & Married & $(-)$ & $(-)$ \\
\hline & Never married & $1.19(\mathrm{p}<0.001)$ & 0.038 \\
\hline & Separated/Divorced & $0.78(\mathrm{p}<0.001)$ & 0.033 \\
\hline & Widowed & $0.77(\mathrm{p}=0.325)$ & 0.206 \\
\hline \multirow[t]{4}{*}{ Education } & Higher & $(-)$ & $(-)$ \\
\hline & None & $3.22(p<0.001)$ & 0.582 \\
\hline & Primary & $5.08(\mathrm{p}<0.001)$ & 0.914 \\
\hline & Secondary & $5.06(\mathrm{p}<0.001)$ & 0.907 \\
\hline \multirow[t]{2}{*}{ Religion } & Non-Christian & $(-)$ & $(-)$ \\
\hline & Christian & $1.10(p=0.035)$ & 0.049 \\
\hline \multirow[t]{2}{*}{ House } & Formal & $(-)$ & $(-)$ \\
\hline & Informal & $1.30(\mathrm{p}<0.001)$ & 0.039 \\
\hline
\end{tabular}

education, women with primary education and women with secondary education $(\mathrm{p}<0.001)$ and between women who resided in formal and informal houses $(p<0.001)$. No significant differences of survival functions were found between women who use contraception and those who do not $(p=0.545)$ and between Christian and non-Christian women $(\mathrm{p}=0.055)$.

The univariate analyses results are presented in Table 2 . The results showed that women who had their first sexual intercourse at age of 16 years or younger were significantly more likely to have had their first births at young ages than women who had their first sexual intercourse at ages over 16 years $(\mathrm{HR}=3.72 ; \mathrm{p}<0.001)$. Women of children who died before exceeding the age of five years were significantly more likely to have had their first births at young ages than women of children who did not die before exceeding the age of five years $(\mathrm{HR}=1.17 ; \mathrm{p}=0.002)$. Women who never had a termination of pregnancy were significantly more likely to have had their first births at a young age than women who had a termination of pregnancy $(\mathrm{HR}=1.34 ; \mathrm{p}<0.001)$.

Women who used contraception were slightly more likely to have had their first births at young ages than women who did not use contraception, but the differences were not statistically significant $(\mathrm{HR}=1.06 ; \mathrm{p}=0.155)$. Women with a total of three or four children $(\mathrm{HR}=0.47 ; \mathrm{p}<0.001)$, women with a total of five to eight children $(\mathrm{HR}=0.23, \mathrm{p}<0.001)$ and women with a total of nine or more children $(\mathrm{HR}=0.18$; $\mathrm{p}<0.001$ ) were significantly less likely to have had their first births at young ages than women with a total of one or two children.

Women who were never married were significantly more likely to have had their first births at young ages than married women $(\mathrm{HR}=1.89 ; \mathrm{p}<0.001)$. However, women who were divorced or separated from their partners were significantly less likely to have had their first births at young ages than married women $(\mathrm{HR}=0.87, \mathrm{p}=0.001)$. Widowed women were less likely to have had their first births at young ages than married women, but the differences were not statistically significant $(\mathrm{HR}=0.81 ; \mathrm{p}=0.421)$. Women with no education $(\mathrm{HR}=3.59 ; \mathrm{p}<0.001)$, women with primary education $(\mathrm{HR}=4.81 ; \mathrm{p}<0.001)$ and women with secondary education $(\mathrm{HR}=5.41, \mathrm{p}<0.001)$ were significantly more likely to have had their first births at young ages than women with higher education levels. Women of Christian religion were more likely to have had their first births at young ages than women of non-Christian religions, but the differences were not statistically significant $(\mathrm{HR}=1.08 ; \mathrm{p}=0.078)$. Women who resided in informal dwelling units or informal houses $(\mathrm{HR}=1.14 ; \mathrm{p}<0.001)$ were significantly more likely to have had their first births at young ages than women who resided in formal dwelling units or formal houses.

The results of the multivariate analysis are presented in Table 3. The results showed that women who had their sexual intercourse at age of 16 years or younger were significantly more likely to have had their first births at a young age than women who had their first sexual intercourse at ages over 16 years $(\mathrm{HR}=4.66 ; \mathrm{p}<0.001)$. Women of children who died before exceeding the age of five years were significantly more likely to have had their first births at young ages than women of children who did not die before exceeding the age of five years $(H R=1.38 ; p<0.001)$. Women who never had a 
termination of pregnancy were significantly more likely to have had their first births at a young age than women who had a termination of pregnancy $(\mathrm{HR}=1.22 ; \mathrm{p}<0.001)$.

Women who used contraception were somewhat more likely to have had their first births at young ages than women who did not use contraception, but the differences were not statistically significant $(\mathrm{HR}=1.02 ; \mathrm{p}=0.611)$. Women with a total of three or four children $(\mathrm{HR}=0.40 ; \mathrm{p}<0.001)$, women with a total of five to eight children $(\mathrm{HR}=0.18, \mathrm{p}<0.001)$ and women with a total of nine or more children $(\mathrm{HR}=0.12$; $\mathrm{p}<0.001$ ) were significantly less likely to have had their first births at a young age than women with a total of one or two children.

Women who were never married were significantly more likely to have had their first births at a young age than married women $(\mathrm{HR}=1.19 ; \mathrm{p}<0.001)$. Contrariwise, women who were divorced or separated from their partners were significantly less likely to have had their first births at a young age than married women $(\mathrm{HR}=0.78 ; \mathrm{p}<0.001)$. Widowed women were less likely to have had their first births at a young age than married women, but the differences were not statistically significant $(\mathrm{HR}=0.77 ; \mathrm{p}=0.325)$. Women with no education $(\mathrm{HR}=3.22 ; \mathrm{p}<0.001)$, women with primary education $(\mathrm{HR}=5.08 ; \mathrm{p}<0.001)$ and women with secondary education $(\mathrm{HR}=5.06, \mathrm{p}<0.001)$ were significantly more likely to have had their first births at a young age than women with higher education levels. Women of Christian religion were significantly more likely to have had their first births at a young age than women of nonChristian religions $(\mathrm{HR}=1.10 ; \mathrm{p}=0.035)$. Women who resided in informal dwelling units or informal houses $(\mathrm{HR}=1.30 ; \mathrm{p}<0.001)$ were significantly more likely to have had their first births at a young age than women who resided in formal dwelling units or formal houses.

\section{DISCUSSION}

The factors associated (or consequences) with early first birth among Angolan women aged 15-49 years have been investigated. Sex leads to pregnancy and pregnancy leads to birth of a child. Early age at first sexual intercourse was significantly associated with the risk of early age at first birth. This implies that the sooner the woman enters into their first sexual intercourse the higher the likelihood that the woman would her first birth at a young age. Rindfuss \& John (1983) stated that one of the most important influences on a young woman's fertility plans is the peer group she is a member of during her early adolescent years [4]. Some peer groups might apply indirect pressure on the young woman to engage in behaviors that either increase the risk of an accidental pregnancy or make early entry into the mother role seem attractive [4]. Peer group pressure and environmental pressure might have played a role in girls to enter into sexual activities at young ages, thus leading to pregnancy and early age at first birth. Children of women who had early first birth were significantly associated with mortality of up to five years. Pebley, Casterline \& Trusell (1982) argued that women who give first births at a young age put their children at risk of childhood mortality and Manda (1999) found that young mothers substantially put their children at a risk of infant mortality [7], [14]. Women who never terminated pregnancy were significantly associated with the increased risk of early age at first birth. Termination of pregnancy, miscarriages and still births postpone early first births [4].

Women with a total of three or more children were significantly negatively associated with the risk of early age at first birth. These could be women who started their respective first births late. They might have prioritised education, economic and marriage stability. They were not associated with the risk of early age at first birth, they might have had to build and increase their respective family sizes as quickly as possible. Women who were never married were significantly associated with early childbearing. The man who impregnated the young woman might have also been young and still was attending school and not ready to get married. Else, the man who impregnated the young woman might have been a married man and could not take the second wife. The women who already have children might have not been married because most men are reluctant to marry a woman who already has a child hence women who were never married were positively associated with the risk of early age at first birth.

Women with no education, women with primary education and women with secondary education were significantly associated with the risk of early first birth as compared to women with higher education. These results are in agreement with the view that young mother face the risk of low educational attainment [7]. Low educational attainment leads to unemployment or low occupational attainment associated with low income, thus leading to poverty [4]. Once the woman has a child, her lifestyle gets affected and changes because of new roles and responsibilities that come with having a child [4]. She should become responsible to raise the child and this makes it difficult for her to concentrate on her own education, thus leading to dropping out of school, dropping out of school further leads to low educational attainment, which in turn leads to unemployment, low income and poverty.

Women of Christian religion were significantly associated with the risk of early first birth as compared to non-Christian women. Engaging into sex before marriage and having a child outside wedlock is considered a sin, immoral and evil in Christianity. Some of the Scriptures that talk about immoral sex and abstention from sex outside marriage include Hebrews chapter 13, verse 4 "Marriage should be honored by all, and the marriage bed kept pure, for God will judge the adulterer and all the sexually immoral" and Colossians chapter 3, verse 5 "Put to death, therefore, whatever belongs to your earthly nature: sexual immorality, impurity, lust, evil desires and greed, which is idolatry", just to mention a few [27]. Women who resided in informal houses were significantly associated with early age at first birth. Residing in an informal house is a sign of poverty. Poverty may lead young women to sleeping with old men in exchange for food, 
clothes, money and other material things that women who are in poverty cannot afford.

\section{CONCLUSION}

The aim of this paper was to determine factors associated with early age at first birth among Angolan women aged 15-49 years. Findings of the study revealed that women who had their first sexual intercourse at a young age, women who never terminated a pregnancy, women who were never married, women with low educational attainments, women of Christian religion and women who resided in informal houses were significantly associated with the risk of early age at first birth as compared to their counterparts. Also, the children of women who had their first births at a young were significantly at risk of dying before exceeding the age of five years.

The results did not reveal significant differences between women who used contraception and those who did not and also between widowed and married women. The reason no significant differences were found between women who use contraception and those who do not might be that women learn about contraception when they are already adults than when they are adolescent. By the time they start to use contraception they might already have had their first births. The use of contraception could have a positive effect on childbearing if women start using contraception from an adolescent stage. Use of contraception from an adolescent stage could extend age at first birth from a young age to an old age. Like married women, widowed women were also married. They might have the similarities of not engaging early into sexual activities and also not having their first children early.

\section{RECOMMENDATIONS}

Delayed childbearing may facilitate economic gains and women's participation in education and the labour force [1]. Sex leads to pregnancy and pregnancy in turn leads to birth of a child. There should be sex education implemented at all schools from primary to secondary level. Children should be taught about the consequences (including human immunodeficiency virus and sexually transmitted diseases) of engaging into sexual activities, especially at a young age. They should be taught about different contraception methods including the use of condoms and be encouraged to focus on education and abstention from sex. Normally parents are uncomfortable to talk to their children about sex, they want to leave it to school teachers. Parents should break this taboo and start to talk to their children about sex in a responsible way. If parents do not talk to their children about sex, then who should? Talking to children about sex from a very young age may reduce the rate of early age at first birth. The country should adopt the slogan "love them enough to talk about sex" [28]-[29]. This slogan was popular in South Africa in the mid 2000s. This slogan will give parents confidence to talk to their children about sex [28]-[29].

Angolan government should establish an organization that focuses on youth development. Through this organisation, programmes focusing at youth health development, teenage pregnancy, counselling and education can be developed to assist children and parents.

\section{LIMITATIONS}

Not all variables could be analysed. Another study should be done to analyse the variables that were not included in this study.

\section{ACKNOWLEDGMENT}

I would like to express my gratitude to the government of Angola for collecting and coordinating the data through the National Institute of Statistics in collaboration with the Ministry of Health and also for making the data available through The DHS Program. I would also like to express my appreciation to Nozimanga Constance Sokana for proof reading this paper.

\section{REFERENCES}

[1] M.R. Decker, A. Kalamar, Ö. Tunçalp, and M.J. Hindin, "Early adolescent childbearing in low-and middle-income countries: associations with income inequity, human development and gender equality," Health Policy and Planning., vol. 32, no. 2, pp. 277 - 282, March 2017.

[2] World Health Organization, "Adolescent pregnancy," 2018.

[3] C.M. Gibbs, A. Wendt, S. Peters, and C.J Hogue, "The impact of early age at first childbirth on maternal and infant health," Paediatric and Perinatal Epidemiology., vol. 26, no. S1, pp. 259 - 284, July 2012.

[4] R.R. Rindfuss, and C. John, "Social determinants of age at first birth," Journal of Marriage and Family., vol.45, no. 3, pp. 553-565, August 1983.

[5] The Demographic and Health Survey Program, "Guide to DHS Statistics: DHS-7," 2018.

[6] J. Mirowsky, "Age at First Birth, Health, and Mortality," Journal of Health and Social Behavior., vol. 46, vol. 1, pp. 32-50, March 2005.

[7] A.R. Pebley, J.B. Casterline, and J. Trussell, "Age at first birth in 19 countries," International Family Planning Perspectives., vol. 8, no. 1, pp. 2-7, March 1982.

[8] M.M. Alam, "Marriage to first birth interval and its associated factors in Bangladesh," Asian Journal of Social Sciences \& Humanities., vol. 4, no. 4, pp. 36-47, November. 2015.

[9] C.M. Pirkle, A.C.P. de Albuquerque Sousa, B. Alvarado, and M.V. Zunzunegui, "Early maternal age at first birth is associated with chronic diseases and poor physical performance in older age: cross-sectional analysis from the International Mobility in Aging Study," BMC Public Health., vol. 14, no. 293, March 2014.

[10] M. Khatun, A.A. Mamun, J. Scott, G.M. William, A. Clavarino, and J.M. Najman, "Do children born to teenage parents have lower adult intelligence? A prospective birth cohort study" Plos One., March 2017.

[11] Schuyler Center for Analysis and Advocacy, "Teenage births: Outcomes for young parents and their children,".

[12] D.R. Morrison, K.A. Moore, D.E. Myers, and B. Maryland, "Maternal age at first birth and children's behavior and cognitive development,".

[13] J.H. Hindin, Ö. Tunçalp, C. Gerdts, J.D. Gipson, and L. Say, "Monitoring adolescent sexual and reproductive health," Bulletin of the World Health Organization., vol. 94, no. 3, pp. 157 - 232, March 2016.

[14] O.M. Manda, "Birth intervals, breastfeeding and determinants of childhood mortality in Malawi," Social Science \& Medicine., vol. 48, no. 3, pp. 301-312, February 1999.

[15] Angola National Institute of Statistics, Ministry of Health, Ministry of Planning and Territorial Development, and ICF, "Key findings of the 2015-16 Angola IIMS," 2017.

[16] W.A Avogo, and O.D. Somefun, "Early marriage, cohabitation, and childbearing in West Africa," Journal of Environmental and Public Health., June 2019. 
[17] Angola National Institute of Statistics., Ministry of Health, Ministry of Planning and Territorial Development., The DHS Programme, and ICF, "Multiple Indicators and Health Survey 2015-2016: Final report," 2017.

[18] E.T. Lee, and J.W. Wang, Statistical methods for survival data analysis. New Jersey: John Wiley \& Sons, 2003.

[19] M.A. Cleves, W.W. Gould, and R.G. Gutierrez, An introduction to survival analysis using STATA. Texas: Stata Corporation, 2003.

[20] P.G. Karadeniz, and I. Ercan, "Examining tests for comparing survival curves with right censored data," Statistics In Transition new series., vol. 18 , no. 2, pp. $311-328$, June 2017.

[21] I. Etikan, K. Bukirova, and M. Yuvali, "Choosing statistical tests for survival analysis," Biometrics \& Biostatistics International Journal., vol. 7, no. 5, pp. 477 - 481, October 2018.

[22] Q. Zaman, and K.P. Pfeiffer, "Survival Analysis in Medical Research," Statistics on the Internet., May 2011.

[23] D.R. Cox, "Regression models and life-tables," Journal of the Royal Statistical Society. Series B (Methodological)., vol. 34, no. 2, pp. $187-$ 220, January 1972.

[24] T. Motsima, K. Zuma, and E. Rapoo, "An investigation of trends and determinants of childhood mortality in South Africa from 1998 to 2012," Ph.D. dissertation, Dept. Stat., Univ. of South Africa., Florida, Johannesburg, South Africa., Dept. Maths. and Stats., Tshwane Univ. of Tech., Pretoria, South Africa., Human Science Research Council., Pretoria, South Africa., Schl. Pub. Health., Univ. of the Witwatersrand., Johannesburg, South Africa, 2019.

[25] D.G. Kleinbaum, and M. Klein, Survival Analysis: A self-learning text. New York: Springer, 2012.

[26] A.R. Cook, "ST3242: Introduction to survival analysis," 2009.

[27] Holy Bible. New International Version.

[28] S. Wilson, "Love them enough to talk about sex," 2005.

[29] LoveLife. https://lovelife.org.za/en/.

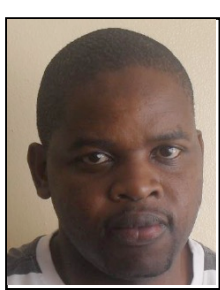

Tshaudi Motsima was born and bred in South Africa. He graduated with BSc in Mathematics and Mathematical Statistics in 2001 followed by BSc honours and MSc, both in Mathematical Statistics, in 2006 and 2007, respectively. All these qualifications were obtained from the University of the Free State in Bloemfontein, South Africa. Further to this, in 2019 he obtained a PhD in Statistics from University of South Africa in Pretoria and Florida, South Africa. He also obtained Advanced Certificate in Education in 2005 from NorthWest University in Vanderbijlpark, South Africa. 